\title{
PERANCANGAN PERBAIKAN FAKTOR DAYA LAMPU TL DENGAN KAPASITOR
}

\author{
Nuraini $^{1}$, Badriana $^{2}$ \\ Jurusan Teknik Elektro Politeknik Negeri Lhokseumawe ${ }^{1}$ \\ Jln. B.Aceh Medan Km.280 Buketrata 24301 \\ Jurusan Teknik Elektro, Fakultas Teknik Universitas Malikussaleh ${ }^{2}$ \\ Kampus Bukit indah, Jalan Batam No. 06 Kecamatan Blangpulo Lhokseumawe \\ E-mail : nuraini.te@pnl.ac.id
}

\begin{abstract}
Abstrak - Laboratorium pendidikan tempat membuktikan teori dan pengujian. Salah satu labortorium di jurusan Teknik Elektro Politeknik Negeri Lhokseumawe yaitu Labortorium Proteksi dan Distribusi, tempat mahasiswa melakukan praktek dan pengembangan ilmu bagi para peneliti dan sebagai pengembangan diri Pranata Laboratorium Pendidikan (PLP), dibidang teknik listrik. Kualitas daya listrik sangat dipengaruhi oleh penggunaan jenis-jenis beban tertentu yang mengakibatkan turunnya efisiensi. Beban yang mempengaruhi kualitas daya listrik adalah beban induktif, seperti; motor induksi, kumparan, ballast, lampu TL. Tujuan dapat menetukan alat dan bahan, serta merangkai pengujian perbaikan faktor daya, yang aman dioprasikan dapat mendukung praktikum serta meningngkatkan keahlian PLP, objek penelitian lampu TL (Tube Lamp) menggunakan kapasitor. Digunakan metode perancangan dan pengukuran, merangkai pengukuran untuk lampu TL dan mengukur besaran listrik, peralatan yang ada di laboratorium dirancang seaman dan semudah mungkin. Telah berhasil merancang rangkaian pengujian perbaikan faktor daya dalam bentuk gambar rangkaian pengujian perbaikan faktor daya, rangkaian ini dapat digunakan untuk mendukung praktikum dan tambahan keahlian bagi PLP bidang teknik listrik khususnya dalam perbaikan faktor daya dengan kapasitor pada system satu phasa. Data hasil pengukuran dapat dijadikan acuan praktikum. Rangkaian semua peralatan aman terisolasi pada ujung dan terminal jumper kabel dan alligator clips sangat kecil kemungkinan terjadi hubung singkat dan tegangan kejut.
\end{abstract}

Keywords - Faktor daya,listrik,rangkaian, rancangan, kapasitor

\section{PENDAHULUAN}

Pemakaian energi listrik pada beban beban listrik, sering menimbulkan problem karena daya yang dikonsumsi tidak sesuai dengan daya yang dibutuhkan oleh beban[1]. Hal ini disebabkan karena faktor daya beban terpasang cukup rendah. Rendahnya kualitas faktor daya yang disebabkan oleh beban listrik yang bersifat induktif. Beban induktif ini akan menyebabkan rendahnya faktor daya $(\operatorname{Cos} \varphi<0,85$ lagging)[2], [3]. Oleh karena itu, agar pemanfaatan energi listrik yang tersedia dapat difungsikan secara optimal, haruslah dilakukan perbaikan faktor daya. Salah satu cara perbaikan faktor daya adalah dengan memasang kapasitor[4], [5].

Kualitas daya listrik sangat dipengaruhi oleh penggunaan jenis-jenis beban tertentu yang mengakibatkan turunnya efisiensi. Jenis-jenis beban yang mempengaruhi kualitas daya listrik adalah beban-beban induktif [6], seperti; motor induksi, kumparan, ballast [7], [8], lampu TL [9], [ 10]. Demikian juga beban-beban non linier seperti; konverter dan inverter untuk drive motor, mesin las, furnace, komputer, ac, tv, lampu TL dan lain-lain[11] [12].

Laboratorium pendidikan merupakan tempat untuk membuktikan teori dan pengujian. Salah satu labortorium di jurusan Teknik Elektro Politeknik Negeri Lhokseumawe yaitu Labortorium Proteksi dan Distribusi, tempat mahasiswa melakukan praktek dan pengembangan ilmu bagi para peneliti dibidang teknik listrik, dan sebagai pengembangan diri Pranata Laboratorium Pendidikan (PLP) selain penataan, perawatan, alat dan bahan di laboraorum, untuk lebih mengenal dan memahami serta dapat memilih alat dan bahan yang sesuai untuk praktikum, mengoprasikan dan merangkai pengjian dengan baik dan benar sesuaidengan, standar oprasional prosedur (SOP), kesehatan dan keselamatan kerja (K3) menggunakan alat pelindung diri (APD) yang sesuai untuk penggunaan alat dan bahan yang dibutuhkan.

\section{DASAR TEORI}

\subsection{Daya}

Daya adalah energi yang dikeluarkan untuk melakukan usaha. Dalam sistem tenaga listrik, daya merupakan jumlah energi listrik yang digunakan untuk melakukan usaha. Pada sistem tenaga listrik, daya listrik dapat dikategorikan dalam 3 jenis yakni, daya Nyata/Daya Aktif (Apparent Power) yang disimbolkan dengan $\mathrm{P}$, adalah daya yang terpakai untuk melakukan energi sebenarnya dengan satuan Watt, daya Reaktif (reactive Power) yang disimbolkan dengan Q, daya yang diperlukan untuk pembentukan medan magnet dengan satuan Volt Amper Reaktif (VAR), dan daya Semu yang disimbolkan dengan S, daya yang dihasilkan oleh perkalian antara tegangan efektif dan arus AC dalam suatu rangkaian dengan satuan Volt Amper (VA). Untuk mengetahui besaran 
listrik pada system yang sebenarnya melakukan pengukuran langsung[13].

Daya dalam rangkaian DC (Direct Current) sama dengan perkalian antara arus dan tegangan. Daya dalam rangkaian AC (Alternating Current) pada setiap saat sama dengan perkalian dari harga daya rata - rata dalam satu periode, sama dengan perkalian antara arus dan tegangan efektif. Tetapi jika ada reaktansi dalam rangkaian, arus dan tegangan tidak sephase selama siklusnya seperti arus bernilai negatif dan tegangan bernilai positif.

Hubungan ketiga daya merupakan hasil penjumlahan trigonometri daya aktif dan daya reaktif diperlihatkan segitiga daya gambar $1[14]$ :

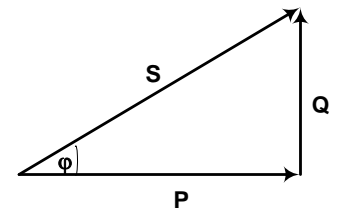

Dimana:

Gambar 2.1. Segitiga Daya

$$
\begin{aligned}
& S=V \times I \text { atau } \\
& S=\sqrt{P^{2}+Q^{2}} \\
& P=V \times I \times \cos \varphi \\
& Q=V \times I \times \sin \varphi \\
& \cos \varphi=\frac{P}{S}
\end{aligned}
$$

\subsection{Perbaikan Faktor Daya}

Faktor daya listrik adalah perbandingan antara daya aktif dengan daya buta, atau dapat dirumuskan sebagai berikut [15] :

$$
\text { Faktor Daya Listrik }=\frac{P}{S}
$$

dimana :

$\mathrm{P}=$ daya aktif dalam Watt

$\mathrm{S}=$ daya buta atau semu dalam VA

Faktor daya listrik ini disebut juga coshinus phi $(\cos \varphi)$, nilai faktor daya listrik 1,0 (perfect aligned) sampai $0,0\left(90^{\circ}\right.$ out of phase). Untuk memperbaiki besarnya faktor daya listrik ini dapat dilakukan dengan memasang kapasitor daya secara paralel terhadap beban listrik tersebut[16], [17]. Hal ini dikarenakan pada faktor daya listrik yang rendah, peralatan listrik banyak menarik daya reaktif induktif sehingga perlu dikompensi dengan daya reaktif kapasitif agar faktor daya listrik dari peralatan tersebut menjadi lebih besar. [13]

Referensi [18], Sumber arus bolak balik (AC = Alternating Current), bila beban yang diaplikasikan bersifat resistif murni, maka gelombang dari tegangan dan arus adalah sefasa. Ditunjukkan pada gambar 2 menunjukkan beban bersifat resistif:

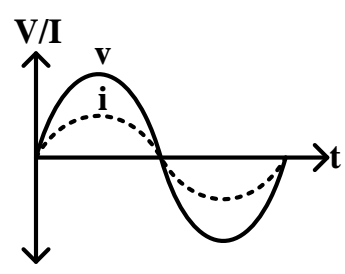

\section{Gambar 2.2 Beban Bersifat Resistif}

Beban bersifat induktif maka yang akan terjadi gelombang arus akan tertinggal dari gelombang tegangan (lagging). Ditunjukkan pada gambar 3 menunjukkan beban bersifat indutif:

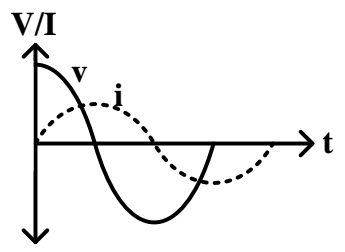

Gambar 2.3 Beban Bersifat Indutif

Beban yang bersifat kapasitif adalah gelombang arus mendahului gelombang tegangannya (leading). Ditunjukkan pada gambar 4 menunjukkan beban bersifat kapasitif:

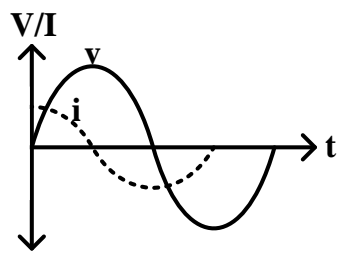

Gambar 2.4 Beban Bersifat Kapasitif

Perhitungan nilai kapasitor digunakan untuk setiap beban yang terpasang pada sistem, sehingga dapat memperbaiki power faktor. Dalam menentukan kapasitansi kapasitor bank dilakukan terlebih dahulu perhitungan daya reaktif kompensator.

Metode perbaikan faktor daya, daya nyata (real) atau daya aktif sebelum dan sesudah perbaikan faktor daya mempunyai nilai yang tetap, seperti dipelihatkan pada gambar 5 .

Daya reaktif konpensator:

$$
\begin{aligned}
& Q_{\text {cap }}=Q_{1}-Q_{2} \\
& Q_{\text {cap }}=P \times\left(\tan \varphi_{1}-\tan \varphi_{2}\right)
\end{aligned}
$$

dimana:

$$
\begin{array}{ll}
\mathrm{P} & : \text { Daya Aktif (watt) } \\
\mathrm{Q}_{\text {cap }} & : \text { Daya Reaktif Kapasitor (VAR) } \\
\varphi_{1} & : \text { sudut sebelum diperbaiki } \\
\varphi_{2} & : \text { sudut setelah diperbaiki }
\end{array}
$$

Untuk lebih jelas perbaikan faktor daya dapat dilihat pada gambar 5[Eaton]. 


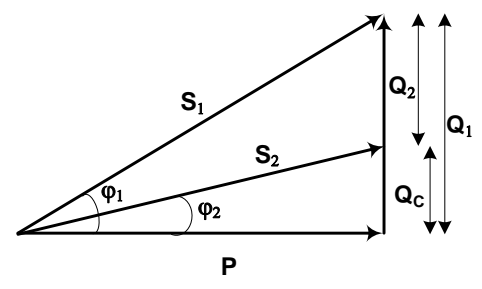

Gambar 2.5 Perbaikan Faktor Daya

Nilai reaktansi kapasitif $X_{C}$ dari kapasitor yang dipasang adalah :

$$
X_{C}=\frac{V^{2}}{Q_{C}}=\frac{V^{2}}{P\left(\tan \varphi_{1}-\tan \varphi_{2}\right)}
$$

Nilai kapasitansi dari kapasitor yang dipasang adalah :

$$
C=\frac{1}{2 \pi f X_{C}}=\frac{P\left(\tan \varphi_{1}-\tan \varphi_{2}\right)}{2 \pi f V^{2}}
$$

\section{METODOLOGI}

Metode peneltian dilkukan kepustakan, perancangan dan pengujian. Pengujian dilakukan emapat tahap yaitu:

Tahap pertama, merangkai Lampu TL dan mengukur besaran listrik dengan sumber tegang satabil dari regulator otomatis. Rangkain dirancang seaman dan semudah mungkin dengan menggunakan peralatan yang ada di laboratorium, seperti pemilihan alat ukur yang sesuai dan kabel penghubung yang aman.

Tahap kedua, data hasil pengukuran digunakan untuk menghitung berapa besar kapasitor yang digunakan untuk menaikan $\operatorname{Cos} \varphi$ ke 0,9 .

Tahap ketiga, memasang kapasitor dan melakukan pengujian mengukur besaran listrik.

Tahap keempat, menganalisa sebelum pemasangan kapasitor dan setelah pemasangan kapasitor

\subsection{Alat dan Bahan}

Perancangan dan pengujian pengukuran diperlukan alat dan bahan. Alat yang digunakan dalam pengukuran alat ukur Analog Digital Multimeter CO5127-1Z. Kabel penghubung jumper safety plug, aligator clip, meja panel Panel ST 7008 - 1N dan toolkit listrik. Bahan yang digunakan dalam penelelitian modul kapasitor daya dan1 set lampu TLD $36 \mathrm{~W}$ philip.

\subsection{Diagram Alir}

Secara garis besar alur penelitian ini dapat dilihat pada diagram alir penelitian gambar 6 .

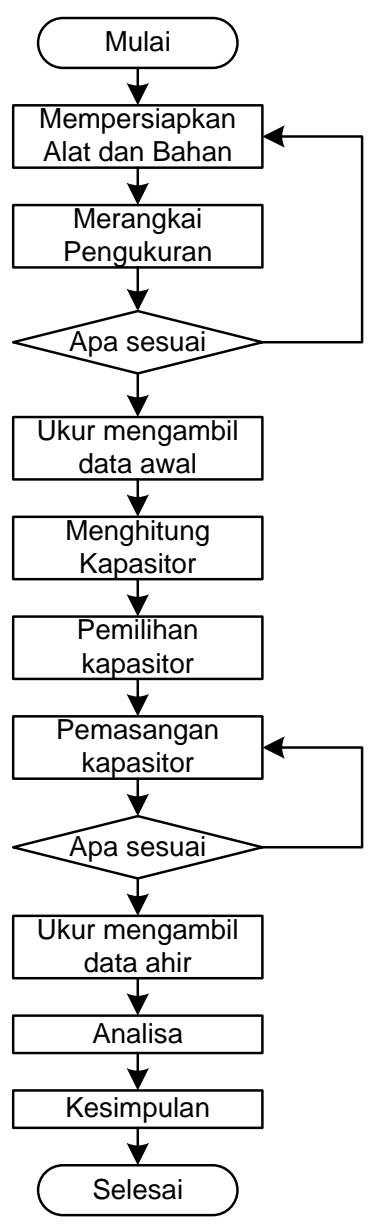

Gambar 3.1. Diagram Alir Penelitian

\section{HASIL DAN PEMBAHASAN}

Rancangan rangkaian pengujian penelitian sebelum dan setelah dipasang kapasitor seperti terlihat pada gambar 4.1.

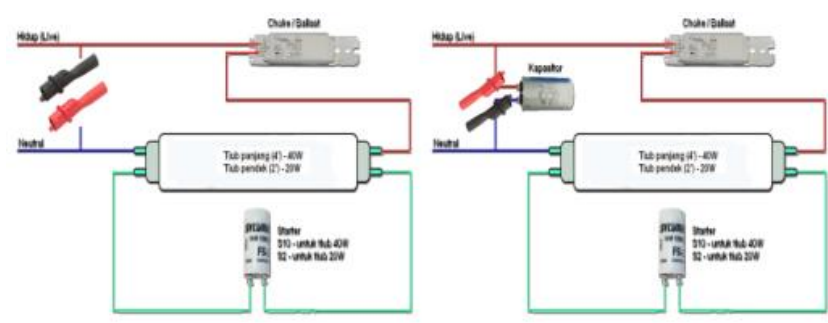

Gambar 4.1. Sebelum Dan Setelah Dipasang Kapasitor 
Alat dan bahan yang digunakan dalam merangkai pengukuran seperti diperlihatkan pada gambar 4.2.

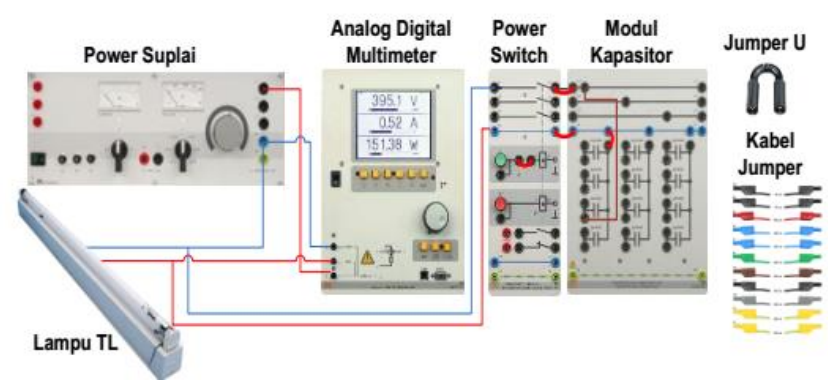

Gambar 4.2. Rangkain Perbaiakan Faktor Daya

Persiapan dan cara merangkai;

Persiapkan alat dan bahan serta buku panduan SOP alat dan bahan mudah di jangkau, seperti terlihat pada gambar 8 , yaitu power suplay ac variabel untuk mengatur tegangan sumber pada 220 Volt ac ST 8008-4S, Analog Digital Multimeter CO 5127-1Z, Power Switch Modul CO3301-5P, Kapasitor Modul CO3301-3E, Jumper U safety plug, Kabel Jumper safety plug, Aligator Cips dan 1set lampu TL.

Merangkai alat dan bahan; Pastikan semua sistem kelistrikan pada meja panel OFF, hubungkan power suplay ke alat ukur dengan kabel jumper warna merah, dari terminal L1 ke terminal COM alat ukur analog digital multimeter, dan hubungkan power suplay ke alat ukur dengan kabel jumper warna biru dari teminal $\mathrm{N}$ ke terminal $\mathrm{U}$ (tegangan) alat ukur analog digital multimeter. Dari terminal I (arus) alat ukur analog digital multimeter keterminal phasa lampu TL menggunakan kabel jumper warna merah dengan dihubungan ke Aligator Clips merah, aligator befugsi menceran terminal lampu TL, dari terminal power suplay $\mathrm{N}$ dihungkan dengan jumper kabel warna biru yang ujung dipasang aligator Clip ke terminal netral Lampu TL.

Pemasangan kapasitor; pilih kapasitor $4 \mu \mathrm{F}$ (sesuai perhitungan) hubungkan terminal com kapasitor ke $\mathrm{N}$ dengan jumper $\mathrm{U}$ dan hubungkan terminal satu lagi ke L1 dengan kabel jumper hitam atau coklat, dari modul kapasitor hungkan ke modul power switch menggunakan jumper $\mathrm{U}$, hubungkan L1 dengan $\mathrm{L} 1$ dan $\mathrm{N}$ dengan $\mathrm{N}$, untuk aktif tombol ON (hijau) dan Tombol OFF (merah) gunakan jumper U untuk menghubungkan terminal pada tombol ON. Hubungkan terminal L1 dan $\mathrm{N}$ modul Power switch ke terminal jumper phasa dan netral pada terminal lampu TL.

Pengoprasian; Pastikan alat pelindung diri baju dan alas kaki atau safety digunakan, hubungkan kabel power alat ukur analog digital multimeter dan modul power switch ke sumber 1phasa dan Power suplay ke terminal soket 3phasa, semua modul yang digunakan jika ada terminal PE (Protection Earth) hubungakna dengan jumper kuning strip hijau ke PE sumber. Periksa kembali rangkain pastikan semua jumper terhubung erat dan ketat, power siwitch setiap modul pada posisi off. Jika semua sudah aman dan yakin tidak ada yang tertinggal. On power suplay utama pada meja panel ST 7008 - 1N menggunakan kunci pengaman, pastikan tombol reset posisi OFF, CB (Circuit Breaker) pada posisi ON, dan ELCB posisi ON, masukan anak kunci keterminal kunci kemudian putar searah jarum jam, jika ada power masuk ditandai dengan bunyi hetakan kontaktor dan indikator phasa L1,L2,L3 menyala, jangan dilepas putaran kunci dan putar tuas slektor switch putar (Rotary Switch) searah jarum jam ke posisi ON (1) lepaskan kunci kemuadian tuas secara berurutan.

Pengukuran; Pastikan alat pelindung diri baju dan alas kaki safety digunakan dengan benar, tekan power switch power suplay ke posisi 1 samapai lampu indikator menyala, dan tekan power switch power analog digital multimeter ke posisi 1, tekan tombol U untuk mengkur tegangan, tombol I untuk mengkur arus, tombol $\mathrm{S}$ untuk mengkur daya semu, tombol $\mathrm{P}$ untuk mengkur daya nyata, tombol $\mathrm{Q}$ untuk mengkur daya reaktif dan tombol $\operatorname{Cos} \varphi$ untuk mengkur paktor daya, alat uukur hanya dapat menampilkan empat pengukuran besaran listrik untuk selanjutnya tkan tombol yang diperlukan, atur tegangan samapai terbaca pada alat ukur 220V shinggga lampu TL menyala. Ambil data pengukuran. Setelah pengambilan data yaitu tegangan, arus, daya semu, daya nyata, daya reaktif dan $\cos \varphi$. Untuk pemasanag kapasitor tekan tombol ON power swich modul warna biru, lakukan pengambilan data yang kedua kalinya yaitu tegangan, arus, daya semu, daya nyata, daya reaktif dan $\cos \varphi$.

Rancangan rangkaian alat pengujian untuk perbaikan faktor atau $\operatorname{Cos} \varphi$ telah berhasil dirancang dan dapat digunakan dengan mudah, aman saat pengoprasian serta dapat digunakan untuk mendukung praktikum pengukuran daya listrik untuk perbaikan faktor daya. Dengan berhasilnya rancangan untuk pengujian faktor daya menambah wawasan dan keahlian peneliti.

Data hasil pengukuran dapat dilihat pada tabel 4.1

Tabel 4.1 Hasil Pengukuran

\begin{tabular}{|c|c|c|c|c|c|}
\hline \multirow{2}{*}{$\begin{array}{c}\text { Tegangan } \\
\text { (Volt) }\end{array}$} & us (Amp & \multicolumn{3}{|c|}{ Daya } & \multirow{2}{*}{ Cos $\varphi$} \\
\cline { 3 - 5 } & & $\begin{array}{c}\text { S } \\
\text { (Watt) }\end{array}$ & (VA) & (Var) & \\
\hline 226 & 0,41 & 45,2 & 91,8 & 79,8 & 0,49 \\
\hline 226 & 0,22 & 45,8 & 50,8 & 21,8 & 0,9 \\
\hline
\end{tabular}

Perhitungan besar kapasitor yang dibutuhkan, dari tabel 1 baris (1) $\cos \varphi$ dan $Q$ yang terukur, untuk menaikkan cos dari 0,49 ke 0,9 .

Jadi $\operatorname{Cos} \varphi_{1}=0,49$ dan $\operatorname{Cos} \varphi_{2}=0,9$

$\mathrm{Q}_{1}=62,9$ dan $\mathrm{Q}_{2}=$ ?

$\mathrm{P}_{1}=\mathrm{P}_{2}=\mathrm{P}=45,2 \mathrm{~W}$

$$
S_{2}=\frac{P_{2}}{\cos \varphi_{2}}=\frac{45,2}{0,9}=50,2 \mathrm{VA}
$$

Dari persamaan (2.2)

$$
\begin{gathered}
Q_{2}=\sqrt{S_{2}^{2}-P^{2}} \\
Q_{2}=21,89 V A R
\end{gathered}
$$

Atau

$$
Q_{2}=S \times \sin \varphi_{2}
$$


Dari $\operatorname{Cos} \varphi_{2}$ dihitung $\operatorname{Sin} \varphi_{2}$

$$
\begin{aligned}
& \operatorname{Cos} \varphi_{2}=(0,9) \\
& \operatorname{Sin} \varphi_{2}=\operatorname{Cos}^{-1}(0,9) \\
& \operatorname{Sin} \varphi_{2}=25,84 \\
& \varphi_{2}=\operatorname{Sin}(25,84) \\
& \varphi_{2}=0,44
\end{aligned}
$$

Maka :

$Q_{2}=50,2 \times \sin (25,8)$

$Q_{2}=50,2 \times 0,44$

$Q_{2}=21,89 V A R$

$\mathrm{Q}_{\text {Cap }}=\mathrm{Q}_{1}-\mathrm{Q}_{2}$

$\mathrm{Q}_{\text {Cap }}=62,9-9,63$

$\mathrm{Q}_{\text {Cap }}=53,27$ Var

Besar kapasitor yang dipasang persamaan (9) adalah :

$$
\begin{gathered}
C_{\text {Cap }}=\frac{1}{2 \pi f X_{C}}=\frac{P\left(\tan \varphi_{1}-\tan \varphi_{2}\right)}{2 \pi f V^{2}} \\
C_{\text {Cap }}=\frac{1}{2 \pi f X_{C}}=\frac{Q_{C}}{2 \pi f V^{2}} \\
C_{\text {Cap }}=\frac{53,27}{2 \times 3,14 \times 50 \times 220^{2}} \\
C_{\text {Cap }}=3,64 \mu \mathrm{F}
\end{gathered}
$$

Karena kapasitor tidak ada 3,64 $\mu \mathrm{F}$ maka digunakan kapasitor yang mendekati yaitu $4 \mu \mathrm{F}$ dan hasil pengukuran menggunakan kapasitor $4 \mu \mathrm{F}$ dapat dilihat pada table 1 baris ke (2). Hasil pengukuran pada table 1 dapat dianalisa penurunan dan kenaikan besaran listriknya, arus (I) turun sebesar 46,34\%, daya semu (S) turun sebesar 44,66\%, daya nya $(\mathrm{P})$ naik sebesar $1,31 \%$, daya reaktif turun $(\mathrm{Q})$ sebesar $72,68 \%$ dan faktor daya atau $\cos \varphi$ naik sebesar $45,56 \%$.

\section{KESIMPULAN}

Penelitian telah berhasil merancang rangkaian pengujian perbaikan faktor daya, rangkaian pengujian perbaikan faktor daya ini dapat digunakan untuk mendukung praktikum dan tambahan keahlian bagi PLP bidang teknik listrik khususnya dalam perbaikan faktor daya dengan kapasitor pada system satu phasa.

Penabahan kapasitor paralel sebesar $4 \mu \mathrm{F}$ dapat menurunkan arus (I) turun sebesar 46,34\%, daya semu (S) turun sebesar $44,66 \%$, daya nya $(\mathrm{P})$ naik sebesar $1,31 \%$, daya reaktif turun (Q) sebesar 72,68\% dan faktor daya atau $\cos \varphi$ naik sebesar $45,56 \%$, sehingga dapat meningkatkan kerja peralatan listrik menurunkan biaya operasional. Data ini dapat digunakan sebagai acuan praktikum.

Untuk mendapatkan harga yang pasti dari besarnya faktor daya listrik, maka haruslah dilakukan pengukuran dengan menggunakan cos phi meter.

Keamanan rangkaian terhadap rangkaian aman karena semua peralatan terselubung isolasi dan pada ujung dan terminal dibuat (safety plug) pada setiap ujung jumper kabel dan alligator clips sangat kecil kemungkina terjadi hubung singkat, dan untuk pelaku praktikum terjadi tegangan sentuhan langsung atau tidak langsung kecil kemungkinan terjadi, karena peralatan dilengkapi dengan pengaman tegangan sentuh dan arus lebih yang dapat diseting sesuai kebutuhan, penggunaan APD yang benar.

\section{REFERENSI}

[1] Rinaldo Jaya Sitorus dan Eddy Warman," Studi Kualitas Listrik Dan Perbaikan Faktor Daya Pada Beban Listrik Rumah Tangga Menggunakan Kapasitor," SINGUDA ENSIKOM VOL.3 NO. 2, Agustus 2013

[2] Supriono dan I Nyoman Wahyu Satiawan," Peningkatan Kinerja Lampu TL (Fluorescent) Pada Catu Daya Dengan Regulasi Tegangan Buruk," Jurnal Teknik Elektro Vol. 5, No. 2, September 2005

[3] Sylvia Handriyani, "Analisa Perbaikan Faktor Daya Untuk Penghematan Biaya Listrik Di Kud Tani Mulyo Lamongan," Jurusan Teknik Elektro FTI - ITS, Januari 2012

[4] Shilpa Murali dan K Jamuna," Power Factor Correction of luorescen Lamp with Electronic Ballast Topology," IJAREEIE, Vol. 4, Issue 4 April 2015

[5] Ardhin Najadiya Setya dan Achmad Imam Agung," Efisiensi Energ Listrik Dalam Upaya Meningkatkan Power Quality dan Penghematan Energi Listrik di Gedung Universitas Ciputra (UC) Apartment Surabaya.” Jurusan Teknik Elektro, Vol. 06, No. 03 Tahun 2017

[6] Baso Mukhlis, "Penghematan Energi Melalui Penggantian Lampu penerangan di lingkungan UNTAD," Jurnal Ilmiah Foristek Vol.1, No.2, September 2011

[7] HID Ballast Application Guide, GE2012-5024 Rev 1, General Elektric, 2012

[8] Ballasts, Some basic facts and some advanced information on ballasts for fluorescent lamps, Ballasts.doc 2006

[9] Didik Riyanto, "Pengaruh Pemakaian Kapasitor Pada Lampu TL Terhadap Efisiensi Daya Listrik Rumah Tangga,” Multitek Indonesia Vol. 7, No.1, Juni 2013 